\title{
THE COMPARATIVE ANALYSIS OF THE TERRITORY FINANCIAL POTENTIAL ASSESSMENT METHODS
}

\author{
Dmytriy V. Nekhaychuk \\ V.I. Vernadsky Crimean Federal University, Simferopol, Russian Federation \\ Alina V. Zhuchik \\ V.I. Vernadsky Crimean Federal University, Simferopol, Russian Federation
}

\begin{abstract}
The article provides the analysis of scientific works on the issues of the territory financial potential assessment methods. According to this analysis there are several fundamentally different approaches to determining the territory financial potential. It is proved that the financial potential of the region is becoming increasingly important today, because in the near future it will determine the state of the economy of the region, the state, as well as occupy one of the main places among state priorities, will affect the financial regional and state policy. The importance of assessing the territory financial potential is also due to the fact that knowing its real state, it becomes possible to effectively and efficiently use all kinds of resources necessary for the region development. The main methodological approaches of assessing the financial potential of the territory are considered: the statistical approach, the comparative approach, evaluation with the use of macroeconomic indicators, the analysis with the use of special indicators, the regression analysis. The main essence of each approach is revealed. The author concludes that despite their diversity, every approach is characterized by certain shortcomings. The bulk of scientists' efforts is focused on calculating the so-called used financial potential, that is, the potential that can actually be implemented in the territory in the near future. At the same time, a significant share of financial potential is an unrealized potential, which requires specific and additional methods of evaluation. Another important drawback is that scientists ignore the existence of the shadow sector, which actually distorts the reality. That is, the methodology for assessing the territory financial potential, despite diverse tools, is not perfect today and requires rethinking in order to approach the economic realities and improve the quality of results.

Key words: financial potential, approach, territory, region, financial resources, credit institution, budget, enterprise.

Citation. Nekhaychuk D.V., Zhuchik A.V. The Comparative Analysis of the Territory Financial Potential Assessment Methods. Vestnik Volgogradskogo gosudarstvennogo universiteta. Seriya 3, Ekonomika. Ekologiya [Science Journal of Volgograd State University. Global Economic System], 2019, vol. 21, no. 2, pp. 133-142. (in Russian). DOI: https://doi.org/10.15688/jvolsu3.2019.2.12
\end{abstract}

\section{СРАВНИТЕЛЬНЫЙ АНАЛИЗ МЕТОДИК ОЦЕНКИ ФИНАНСОВОГО ПОТЕНЦИАЛА ТЕРРИТОРИИ}

\author{
Дмитрий Валериевич Нехайчук
}

Крымский федеральный университет им. В.И. Вернадского, г. Симферополь, Российская Федерация

\author{
Алина Владиславовна Жучик
}

Крымский федеральный университет им. В.И. Вернадского, г. Симферополь, Российская Федерация 
Аннотация. В статье представлен анализ научных трудов по вопросам методологии оценки финансового потенциала территории, исходя из которого выяснено несколько принципиально различных подходов к определению финансового потенциала территории. Доказывается, что финансовый потенциал региона на сегодняшний день и в перспективе приобретает все большее значение, ведь именно он будет определять в ближайшем будущем состояние экономики региона, государства, а также одно из главных мест среди государственных приоритетов, будет влиять на финансовую региональную и государственную политику. Важность оценки финансового потенциала территории также обусловливается тем, что, зная реальное его состояние, возможно эффективно и рационально использовать все виды ресурсов, необходимые для развития региона. Рассмотрены основные методические подходы оценки финансового потенциала территории: статистический подход, сравнительный анализ, оценка с использованием макроэкономических показателей, анализ с помощью специальных показателей, регрессионный анализ. Раскрыта основная суть каждого из подходов. Делается вывод, что, несмотря на их многообразие, для всех характерны определенные недостатки. Основная масса усилий ученых сосредоточена на расчете так называемого используемого финансового потенциала, то есть того, что фактически может быть реализовано на данной территории на протяжении ближайшего времени, в то время как значительную долю финансового потенциала составляет нереализованный потенциал, что требует специфических и дополнительных методов оценки. Еще одним важным недостатком является игнорирование учеными факта существования теневого сектора, что фактически искажает реальное положение вещей. То есть методология оценки финансового потенциала территории, несмотря на достаточно разнообразный инструментарий, на сегодня не является совершенной и требует переосмысления с целью приближения к экономическим реалиям и повышения качества результатов.

Ключевые слова: финансовый потенциал, подход, территория, регион, финансовые ресурсы, кредитная организация, бюджет, предприятие.

Цитирование. Нехайчук Д. В., Жучик А. В. Сравнительный анализ методик оценки финансового потенциала территории // Вестник Волгоградского государственного университета. Серия 3, Экономика. Экология. -2019. - Т. 21, № 2. - С. 133-142. - DOI: https://doi.org/10.15688/jvolsu3.2019.2.12

\section{Введение}

В условиях рыночных трансформаций российской экономики важной задачей новой региональной политики становится формирование эффективных региональных социальноэкономических систем, устранение социально-экономических диспропорций в первую очередь за счет устойчивых финансовых возможностей, привлечения регионов к международному сотрудничеству и т. п. В этом контексте усиливается роль региональных финансов, а вопросы эффективного управления финансовым потенциалом, наращивание финансовых возможностей региона и повышение эффективности использования имеющихся ресурсов и резервов приобретают особую значимость.

На сегодняшний день и в перспективе финансовый потенциал приобретает все большее значение, ведь именно он будет определять в ближайшем будущем состояние экономики региона, государства, а также одно из главных мест среди государственных приоритетов, будет влиять на финансовую региональную и государственную политику, поэтому исследование заключается в поиске адекватной методологии его оценки.

Без объективной и качественной оценки объекта управленческого влияния невозможно эффективное управление экономическими процессами. Процесс оценки в управлении финансовым потенциалом представляет собой формирование законченного представления о ценности и значении этого объекта для субъекта управления.

Важность оценки финансового потенциала территории также обусловливается тем, что, зная реальное его состояние, возможно эффективно и рационально использовать все виды ресурсов, необходимые для развития региона. Кроме того, уровень финансового потенциала выступает индикатором целесообразности вложения финансовых ресурсов внешних инвесторов в инвестиционную деятельность региона.

Обобщение результатов исследований по проблематике управления финансовым потенциалом свидетельствует, что в зарубежной и отечественной практике аккумулирован значительный опыт его оценки, однако целостная общепринятая методология сегодня отсутствует. Механизм регионального финансового сравнения и со- 
четания базируется в основном на показателях, направленных на оценку сбалансированности расходных статей бюджета и полученных налоговых платежей. В связи с этим возникает необходимость разработки комплексного подхода к оценке финансовых возможностей региона, учитывающей все его элементы.

Анализ сущности финансового потенциала и факторов, на него влияющих, показал, что данное понятие является комплексным и достаточно сложным. Это, как правило, отражается в методических подходах к оценке уровня финансового потенциала территории.

Проведенный анализ научных трудов по вопросам методологии оценки финансового потенциала показал, насколько принципиально различны подходы к определению финансового потенциала территории. Наиболее распространенными методическими подходами можно назвать следующие:

1) статистический подход или метод оценки финансовых ресурсов;

2) сравнительный подход;

3) оценка с использованием макроэкономических показателей;

4) анализ с помощью специальных показателей;

5) регрессионный анализ.

\section{Результаты исследования}

Рассмотрим сущность и особенности использования указанных методических подходов. Начнем с наиболее широко применяемой группы методических подходов, построенных по статистическим методам.

Использование поэлементного статистического подхода к оценке финансового потенциала территории характерно для целого ряда исследователей. Он отличается в первую очередь составными элементами финансового потенциала, а также перечнем показателей, используемых для оценки этих составляющих.

Согласно подходу, разработанному Д.А. Гайнановым и А.Г. Япаровой, оценка финансового потенциала заключается в нахождении суммы финансовых ресурсов по таким структурным элементам, как бюджетный потенциал, финансовый потенциал предприятий, финансовый потенциал населения [Гайнанов и др., 2009].
К показателям, характеризующим уровень бюджетного потенциала, относят налоговые и неналоговые доходы бюджета, бюджетные трансферты. Финансовый потенциал предприятий предлагается оценивать как сумму прибыли, амортизации и предпринимательского дохода. Финансовый потенциал населения составляют денежные доходы населения.

Данной методикой предусматривается расчет финансового потенциала в трех измерениях:

- по структурным элементам и в целом в денежном выражении (для определения объема финансовых ресурсов, генерируемых территорией);

- по структурным элементам и в целом в денежном выражении на душу населения (с целью определения обеспеченности населения финансовыми ресурсами и проведения сравнения с финансовыми потенциалами других территорий);

- по структурным элементам и в целом в нормированном виде (для кластеризации территориальных образований, входящих в состав анализируемой территории) [Гайнанов и др., 2009].

Данный подход, по нашему мнению, в основном касается оценки фактически реализованного финансового потенциала и не учитывает целый ряд важных финансовых ресурсов, например инвестиции, финансовые ресурсы кредитных организаций и небанковских финансовых учреждений, наличие сбережений у населения, основные средства предприятий. Таким образом, данный подход к оценке финансового потенциала дает лишь поверхностное представление, которое не позволяет оценить реальное состояние финансового потенциала территории.

Более расширенный подход к оценке финансового потенциала разработан Ю.И. Булатовой. Оценку предлагается осуществлять путем определения объемов:

- бюджетно-инвестиционного потенциала территории (профицит бюджета, средства бюджета, направленные на инвестиционные цели);

- финансовых ресурсов населения (вклады населения в ценные бумаги, в недвижимость и имущество, а также остаток неиспользованных средств); 
- собственных финансовых ресурсов организаций (прибыль и амортизационные отчисления);

- финансовых ресурсов финансово-кредитных организаций (совокупность средств, привлеченных у физических и юридических лиц за исключением резервов под эти операции);

- финансовых ресурсов внешних заимствований (сумма средств, перераспределенных из бюджетов других уровней, а также иностранные инвестиции и заимствования) [Булатова, 2011].

Несмотря на более расширенный перечень составляющих финансового потенциала в данном подходе, он выступает, по нашему мнению, неполным и местами противоречивым. Так, например, сбережения населения, составляющие основу финансового потенциала данной составляющей, не включены в показатели ее расчета. Еще одним примером могут быть собственные финансовые ресурсы организации, которые включают в себя только прибыль и амортизацию. Однако сюда можно отнести также средства на текущем счете или в кассе, дебиторскую задолженность и даже потенциально возможные привлеченные ресурсы путем эмиссии акций или облигаций. Такие методологические недостатки характерны для каждой из составляющих, что делает невозможным проведение реальной и адекватной оценки финансового потенциала при использовании данной методики в исключительно авторском виде.

Следующими рассмотрены методические подходы для оценки финансового потенциала территории, разработанные Т.Б. Ивановой и Р.А. Прокопенко [Иванова и др., 2008, c. 155-157]. Оценку предлагается проводить путем определения текущего финансового потенциала (материальные затраты на производство продукции, товаров, услуг и расходов домохозяйств на покупку товаров и оплату услуг), инвестиционного финансового потенциала (прибыль предприятий, амортизация, вложения в основной капитал, прирост запасов, краткосрочные финансовые вложения, объем сбережений населения), бюджетного потенциала (налоговые и неналоговые поступления, которые могут быть аккумулированы в рамках конкретной территории).
Недостатками данного подхода можно назвать отсутствие такой составляющей, как финансовый потенциал финансово-кредитных учреждений, частичный учет потенциала субъектов хозяйственной деятельности, отсутствие финансового потенциала, что генерируется внешними источниками (инвесторами, материнскими компаниями, материальной помощью и другими трансфертами из-за рубежа) [Иванова и др., 2008].

Ж.Г. Голодова предлагает количественную оценку финансового потенциала как результат взаимодействия следующих элементов: потенциал предприятий и организаций, бюджетно-налоговый потенциал, потенциал кредитных организаций, страховых компаний, инвестиционных и пенсионных фондов, домашних хозяйств [Голодова, 2010].

Основу бюджетно-налогового потенциала составляют налоговые и неналоговые доходы бюджетов территорий, а также средства, поступающие из других бюджетов. Потенциал предприятий и организаций включает в себя прибыль и амортизационные отчисления. Потенциал кредитных организаций состоит из собственных и привлеченных средств банков и небанковских учреждений, а также балансовой стоимости их имущества. Потенциал страховых компаний, инвестиционных и пенсионных фондов состоит из собственных и мобилизованных средств. Финансовый потенциал домохозяйств включает средства в виде сбережений вне банковской системы.

Положительным моментом данного подхода можно считать акцентирование значительного внимания на финансовой инфраструктуре территории как источника финансовых ресурсов. Однако выбор для оценки финансового потенциала предприятий неваловых доходов или суммы активов предприятия, а лишь прибыли и амортизационных отчислений является достаточно спорным. Кроме того, как и в предыдущей методике, отсутствуют сведения о финансовых ресурсах, генерируемых внешними субъектами и поступающих на территорию в виде иностранных инвестиций, материальной помощи или обычных денежных переводов [Голодова, 2010].

Следующий поэлементный подход к оценке финансового потенциала разработан Т.А. Стеценко и А.П. Тищенко, в котором сум- 
ма финансового потенциала территории равна сумме финансовых ресурсов, генерируемых в рамках перечня следующих элементов:

- бюджет территории и внебюджетные фонды;

- ценные бумаги, эмитированные органами власти территории;

- финансовые ресурсы предприятий и организаций всех форм собственности;

- средства населения, которые находятся у него на руках или в банках и других финансовых институтах, а также в виде различных ценных бумаг;

- финансовые ресурсы кредитно-банковской системы территории, а также средства, привлекаемые местными кредитными организациями с других территорий [Стеценко, 2002].

Н.М. Сабитовой предлагает рассчитывать финансовый потенциал территории на основе учета его использованных и неиспользованных ресурсов (природных, интеллекту- альных, налоговых и пр.). По мнению исследователя, их оценку необходимо производить по величине доходов, которую они могут принести в случае привлечения. Для природных ресурсов предлагается использовать рентный подход, для основных фондов - метод капитализации (см. подробнее: [Зенченко, 2008, c. 186-198]).

Р.А. Прокопенко предлагает разделять финансовый потенциал территории на две составляющие - реализован и не реализован [Прокопенко, 2008]. В таблице приведен перечень показателей оценки финансовых потоков, составляющих финансовый потенциал.

Таким образом, статистический подход оценки финансового потенциала у большинства ученых заключается в определении перечня показателей, его формирующих, с последующим сведением их к единому измерителю (денежного) и определении арифметической суммы значений этих показателей.

Таблииа

Показатели оценки финансовых потоков, составляющие финансовый потенциал

\begin{tabular}{|c|c|c|}
\hline $\begin{array}{c}\text { Вид финансового } \\
\text { потенциала }\end{array}$ & Характеристика вида финансового потенциала & Показатели оценки финансовых потоков \\
\hline \multicolumn{3}{|c|}{ Реализованный финансовый потенциал территории } \\
\hline $\begin{array}{l}\text { Первичный } \\
\text { потенциал }\end{array}$ & Общий объем изготовленной продукции & $\begin{array}{l}\text { - объем отгруженных товаров собственного } \\
\text { производства в промышленности; } \\
\text { - объем отгруженных товаров собственного } \\
\text { производства сельскохозяйственных предпри- } \\
\text { ятий; } \\
\text { - оборот розничной торговли; } \\
\text { - оборот общественного питания; } \\
\text { - объем платных услуг }\end{array}$ \\
\hline $\begin{array}{l}\text { Текущий потенциал } \\
\text { предприятий }\end{array}$ & $\begin{array}{l}\text { Промежуточное потребление в процессе } \\
\text { производства }\end{array}$ & $\begin{array}{l}\text { Затраты на производство продукции (себе- } \\
\text { стоимость) }\end{array}$ \\
\hline $\begin{array}{l}\text { Инвестиционный } \\
\text { потенциал предпри- } \\
\text { ятий }\end{array}$ & Валовое накопление фирм & $\begin{array}{l}\text { Инвестиции в основной капитал за счет всех } \\
\text { источников финансирования в действующих } \\
\text { ценах каждого года }\end{array}$ \\
\hline $\begin{array}{l}\text { Текущий потенциал } \\
\text { домохозяйств }\end{array}$ & $\begin{array}{l}\text { Затраты на конечное потребление домохо- } \\
\text { зяйств }\end{array}$ & $\begin{array}{l}\text { - расходы на покупку товаров; } \\
\text { - оплата услуг; } \\
\text { - обязательные платежи и различные взносы }\end{array}$ \\
\hline $\begin{array}{l}\text { Текущий потенциал } \\
\text { бюджета }\end{array}$ & $\begin{array}{l}\text { Расходы бюджета на финансирование те- } \\
\text { кущих расходных полномочий }\end{array}$ & $\begin{array}{l}\text { - доходы местного бюджета, в том числе } \\
\text { средства в рамках межбюджетных отношений }\end{array}$ \\
\hline $\begin{array}{l}\text { Инвестиционный } \\
\text { потенциал бюджета }\end{array}$ & $\begin{array}{l}\text { Расходы бюджета на финансирование раз- } \\
\text { вития территории }\end{array}$ & $\begin{array}{l}\text { Расходы бюджета на финансирование разви- } \\
\text { тия территории }\end{array}$ \\
\hline $\begin{array}{l}\text { Общий финансовый } \\
\text { потенциал с учетом } \\
\text { утечек и удалений }\end{array}$ & $\begin{array}{l}\text { Общий объем продукции, скорректиро- } \\
\text { ванный на величину перераспределения } \\
\text { средств по межбюджетным отношениям }\end{array}$ & $\begin{array}{l}\text { Общий объем выпущенной продукции, скор- } \\
\text { ректированный на величину перераспределе- } \\
\text { ния средств по межбюджетным отношениям }\end{array}$ \\
\hline \multicolumn{3}{|c|}{ Нереализованный финансовый потенциал территории } \\
\hline $\begin{array}{l}\text { Потенциал } \\
\text { домохозяйств }\end{array}$ & \multicolumn{2}{|l|}{ Разница между доходами и расходами } \\
\hline Потенциал фирм & \multicolumn{2}{|c|}{ Разница между валовыми сбережениями и накоплениями } \\
\hline $\begin{array}{l}\text { Суммарный } \\
\text { потенциал }\end{array}$ & \multicolumn{2}{|c|}{$\begin{array}{l}\text { Разница между общим финансовым потенциалом (с учетом утечек и изъятий) и суммарным } \\
\text { текущим и инвестиционным потенциалом предприятий и домохозяйств }\end{array}$} \\
\hline
\end{tabular}

Примечание. Источник: [Прокопенко, 2008]. 
Основными недостатками данного подхода являются: отсутствие четкого перечня показателей, плюрализм мнений относительно особенностей формирования такого перечня, необходимость расчета большого количества показателей, который приводит к росту объемов информации, подлежащей обработке. При этом полученные результаты являются достаточно условными и со значительной погрешностью с точки зрения сущности финансового потенциала.

Исходя из этого, более простым вариантом комплексного оценивания финансового потенциала объекта выступает сравнительное исследование нескольких объектов с целью выявления более эффективных и динамичных в отношении других.

Информация о максимальных возможностях при данных условиях в таком случае заложена в показателях лучших объектов исследования. Данная методология получила название сравнительный подход определения финансового потенциала, когда статистический подход оценивает имеющиеся и частично потенциальные финансовые ресурсы с различными составляющими, не давая и не используя при этом информацию относительно уровня использования финансового потенциала. Такая информация о конкретном регионе вместе с сравнением ее с информацией о других регионах предоставляет дополнительные или альтернативные возможности для оценки финансового потенциала. Именно эта логика и составляет основу сравнительного подхода.

Согласно этой методологии формируется база информации о генерации финансовых ресурсов тем или иным показателем (например, объем сбережений на душу населения, средний размер активов кредитной организации, объем налоговых поступлений с одного предприятия и т. п.). С позиции определения размера финансового потенциала уместно брать не средние по стране, а максимальные значения объемов генерируемых финансовых ресурсов. Далее формируется набор корректирующих коэффициентов, которые бы отражали специфику той или иной территории. Итоговым этапом является расчет финансового потенциала региона, когда на базе показателей конкретного региона с учетом потенциала их реализации по генерации финансовых ресурсов определяется размер финансовых ресурсов, которые может производить данная территория.

Величина финансового потенциала территории зависит не только от качества работы предприятий, отраслей экономики, но и от ряда других факторов. Так, например, в промышленности на одного работника приходится прибыли значительно больше, чем в сельском хозяйстве. Кроме того, есть отрасли априори более доходные и прибыльные, чем другие (например, нефтегазовая, алкогольная, табачная и т. п.). Таким образом, недостатком данного подхода выступает неучет того факта, что территории не являются абсолютно ровными как по природным условиям, так и по экономической структуре, соответственно потенциальные возможности их отличаются [Ахмедов, 2005].

Еще одной группой методов оценки финансового потенциала территории является оценка с использованием макроэкономических показателей. В соответствии с этим подходом рассчитывается результирующий показатель финансово-экономической деятельности территории, который и будет использоваться как база для расчета финансового потенциала. На уровне государства таким показателем является ВВП, а для территорий - ВРП (валовой региональный продукт).

Именно такой подход использовали А.Л. Коломиец и Н.А. Новикова при разработке подхода к оценке финансового потенциала:

$$
\text { ФПР }=\sum_{i=1}^{n} \mathrm{HБ}_{i} \times \mathrm{K}_{i} \times \mathrm{BP},
$$

где ФПР - финансовый потенциал региона; $\mathrm{HБ}_{i}-$ национальное богатство $i$-го элемента; $K_{i}$ - коэффициент ликвидности $i$-го элемента; $n-$ количество элементов национального богатства; ВРП - валовой региональный продукт.

Под национальным богатством фактически понимается количество финансовых ресурсов на единицу ВРП.

Что касается коэффициентов ликвидности, то они выбираются достаточно условно, исходя из стандартных соотношений (например, коэффициенты ликвидности по различным группам активов баланса предприятия или банка). Так, балансовая стоимость основных 
средств - коэффициент 0,1 , оборотные средства предприятий в запасах товарно-материальных ценностей - 0,5, а денежные средства населения в банках - 1 [Конярова, 2005].

Проблемой данного подхода является то, что уровень надежности и достоверности полученных оценок финансового потенциала территории будет определяться достоверностью оценок рыночной стоимости элементов национального богатства, а также адекватностью коэффициентов ликвидности, которые почти всегда будут иметь субъективный характер [Ахмедов, 2005].

Одним из вариантов оценки финансового потенциала выступает построение уравнений регрессии, которые бы описывали зависимость между финансовым потенциалом и конкретными финансовыми потоками, его формирующими. Считается, что данный подход является наиболее точным из всех анализируемых выше.

Метод регрессионного анализа позволяет не только свести разрозненные с точки зрения измерения величины (численность населения, количество предприятий, налоговые ставки, объемы внешней торговли, ВВП, уровень инфляции и т. д.) к единому денежному знаменателю, но и, используя прогнозы из разных источников (Министерство финансов России, Центральный банк России, МВФ, аналитические агентства, независимые эксперты и др.), рассчитать различные варианты значений генерируемых финансовых ресурсов, условно разделив их на оптимистический сценарий, пессимистический, консервативный и т. д.

По мнению С.М. Фролова [Фролов, 2010], с точки зрения оценки финансового потенциала наиболее интересной является линейная многофакторная модель, поскольку позволяет не только спрогнозировать будущее значение фактического потенциала, но и, что главное, дает возможность оценить номинальный потенциал, то есть максимальную способность по формированию финансовых ресурсов.

Линейная многофакторная регрессия выглядит следующим образом:

$$
Y=b+a_{1} \times x_{1}+a_{2} \times x_{2}+\ldots+a_{n} \times x_{n}
$$

где $Y$ - зависимая переменная, результирующий фактор - объем финансового потенциала террито- рии в денежных единицах; $b$ - свободный член, который фактически показывает размер смещения теоретического распределения относительно фактического и является константой; $x_{1}, x_{2}, \ldots, x_{n}$ - независимые переменные, набор факторов, определяющих размер бюджетного потенциала, оказывают наибольшее влияние на его формирование; $a_{1}$, $a_{2}, \ldots, a_{n}$ - коэффициенты при соответствующих переменных модели. Они нормируют размерность переменных, сводя ее к одному знаменателю (в нашем случае деньги), а также характеризуют степень влияния каждой из переменных на итоговый результат.

С точки зрения оценки номинального потенциала интересным является знак коэффициента. Если он невидимый, то существует прямая зависимость между зависимым и независимым факторами. Если он отрицательный, то такая связь является обратной и фактически указывает на размер недоиспользование потенциала, то есть возникает возможность оценить номинальный (максимально возможный) потенциал при заданных условиях. Для этого переменные, осуществляющие негативное воздействие, приравниваются к нулю. Полученное значение зависимой переменной и будет максимально возможным финансовым потенциалом при данных условиях [Фролов, 2010].

Недостатком регрессионного подхода выступает его относительная сложность, а также необходимость наличия достаточного количества точек наблюдения для формирования адекватной модели. В случае, например, с Крымским регионом и его относительно молодой экономической и статистической системой с момента присоединения к Российской Федерации эта проблема вообще является первоочередной.

Ряд ученых, говоря об оценке финансового потенциала территории, предлагают использовать не арифметическую оценку финансовых потоков, генерируемых в рамках конкретной территории, а скорее, оценивать способность к генерации этих потоков, которая, в свою очередь, зависит от целого ряда факторов. Влияние этих факторов предлагается оценивать с помощью расчета показателей, которые, с одной стороны, дают общую характеристику территории (площадь, количество населения), а с другой - характеризуют состояние и объем источников фор- 
мирования финансовых ресурсов территории (объем валового регионального продукта, наличие основных средств, объемы розничной торговли и др.).

Важной составляющей оценки финансового потенциала территории является определение уровня его использования. Единого подхода по этому поводу среди ученых нет. Отметим лишь, что большинство ученых предлагают использовать с этой целью элементы сравнительного подхода, о котором сказано выше - при анализе методов оценки величины финансового потенциала.

\section{Выводы}

Анализ методик оценки уровня финансового обеспечения региона показал, что наиболее адекватно отражают уровень потенциальных финансовых возможностей региона те методики, которые выполнены на основе расчета интегрального показателя финансового потенциала. Такие методики позволяют оценить не только величину потенциала на основе показателей уровня обеспеченности инвестиционными, бюджетными, налоговыми, инновационными ресурсами отдельных регионов и в конечном итоге интегрального индекса финансового потенциала, что является важным для определения перспектив регионального развития, но и уровень эффективности и адекватности его использования, что, по нашему мнению, может служить основой для разработки необходимых корректирующих управленческих решений.

Несмотря на многообразие подходов к оценке финансового потенциала территории, для всех них характерны определенные недостатки. Так, большинство ученых игнорируют тот факт, что финансовый потенциал - это в первую очередь способность к генерации определенного объема финансовых ресурсов, поэтому является величиной вероятностной. Таким образом, оценка потенциала обязательно должна содержать несколько сценариев: оптимистический, пессимистический и реальный с определением вероятностей, с которыми каждый из сценариев может быть реализован. К сожалению, проведенный нами анализ показал, что такие оценки выполняются, а альтернативные сценарии не разрабатываются.
Кроме того, основная масса усилий ученых сосредоточена на расчете так называемого используемого финансового потенциала, то есть того, что фактически может быть реализовано на данной территории на протяжении ближайшего времени, в то время как значительную долю финансового потенциала составляет нереализованный потенциал, что требует специфических и дополнительных методов оценки, таких как определение настроений потребителей, инвесторов, определение бизнес-климата территории и перспектив ее развития.

Еще одним важным недостатком является игнорирование учеными факта существования теневого сектора, что фактически искажает реальное положение вещей. Большинство методик касается анализа официальной экономики, в то время как часть ее находится в тени.

Таким образом, методология оценки финансового потенциала территории, несмотря на достаточно разнообразный инструментарий, на сегодня не является совершенной и требует переосмысления с целью приближения к экономическим реалиям и повышения качества результатов.

Следует отметить, что оценку финансового потенциала территории и разработку путей дальнейшего стимулирования ее роста как основы экономического развития, повышения эффективности его использования, обеспечения системного управления и использования муниципальными органами власти возможно осуществить, лишь учитывая все финансовые потоки территории.

\section{СПИСОК ЛИТЕРАТУРЫ}

Ахмедов, А. Б. Финансовый потенциал региона и его использование в системе межбюджетных отношений : автореф. дис. ... канд. экон. наук / Ахмедов А. Б. - Махачкала, 2005. - 27 с.

Беляков, Д. Е. Развитие социально-экономического потенциала регионов в условиях рыночной экономики / Д. Е. Беляков. - М., 2001. - 165 с.

Булатова, Ю. И. Формирование финансового потенциала инвестиционной деятельности субъекта Российской Федерации : автореф. дис. ... канд. экон. наук / Булатова Ю. И. - Оренбург, 2011. - 21 c.

Гайнанов, Д. А. Оценка и механизм управления финансового потенциалом муниципального 
образования / Д. А. Гайнанов, А. Г. Япарова // Вестник БИСТ. - 2009. - № 2 (2). - С. 77-94.

Голодова, Ж. Г. Формирование и управление финансового потенциалом региона в целях обеспечения его экономического роста : автореф. дис. ... д-ра экон. наук / Голодова Ж. Г. - М., 2010. - 44 с.

Зенченко, С. В. Бюджетный потенциал региона и методические подходы к его оценке / С. В. Зенченко // Региональные проблемы преобразования экономики. - 2008. - № 1. - С. 186-198.

Иванова, Т. Б. Методические подходы к оценке регионального финансового потенциала / Т.Б.Иванова, Р. А. Прокопенко // Фундаментальные исследования. - 2008. - № 1-С. 155-157.

Конярова, Э. К. Управление воспроизводством финансового потенциала региона : автореф. дис. ... д-ра экон. наук / Э. К. Конярова. Ижевск, 2005. - 20 с.

Прокопенко, Р. А. Оценка и направления развития финансового потенциала региона : автореф. дис. ... д-ра экон. наук / Прокопенко Г. А. Волгоград, 2008. $-27 \mathrm{c}$.

Стеценко, Т. О. Анализ региональной экономики : учеб. пособие / Т. О. Стеценко. - Киев : КНЭУ, 2002. - $116 \mathrm{c}$.

Фролов, С. М. Бюджетный менеджмент и проблемы развития приграничных территорий : монография / С. М. Фролов. - Сумы : Изд-во Сумского гос. ун-та, 2010. - 316 с.

Цыбульская, Э. И. Теоретические основы оценки экономического потенциала предприятия / Э. И. Цыбульская, А. В. Сотник // БИЗНЕСИНФОРМ. -2009. - № 3. - С. 58-61.

\section{REFERENCES}

Akhmedov A.B. Finansovyj potencial regiona i ego ispol'zovanie $v$ sisteme mezhbjudzhetnyh otnoshenij [The Financial potential of the region and its use in the system of inter-budgetary relations]. Makhachkala, 2005. $27 \mathrm{p}$.

Belyakov D.E. Razvitie social'no-jekonomicheskogo potenciala regionov $v$ uslovijah rynochnoj jekonomiki [Development of social and economic potential of regions in the conditions of market economy]. Moscow, 2001. 165 p.

Bulatov Yu.I. Formirovanie finansovogo potenciala investicionnoj dejatel'nosti subekta Rossijskoj
Federacii [Formation of the financial potential of investment activity of the Russian Federation: abstract]. Orenburg, 2011.21 p.

Gajnanov D.A. Ocenka i mehanizm upravlenija finansovogo potencialom municipal'nogo obrazovanija [Assessment of the financial potential of the municipality and the mechanism of management of the financial capacity of the municipality]. Vestnik BIST [Messenger BIST], 2009, no. 2 (2), pp. 77-94.

Golodova Zh.G. Formirovanie $i$ upravlenie finansovogo potencialom regiona $v$ celjah obespechenija ego jekonomicheskogo rosta [The Formation and management of the financial potential of the region to ensure its economic growth]. Moscow, 2010. 44 p.

Zenchenko S.V. Bjudzhetnyj potencial regiona i metodicheskie podhody k ego ocenke [Budget potential of the region and methodological approaches to its assessment]. Regional'nye problemy preobrazovanija jekonomiki, 2008, no. 1, pp. 186-198.

Ivanova T.B. Metodicheskie podhody $\mathrm{k}$ ocenke regional'nogo finansovogo potenciala [Methodical approaches to evaluation of regional financial capacity]. Fundamental'nye issledovanija, 2008, no. 1, pp. 155-157

Konjarova Je.K. Upravlenie vosproizvodstvom finansovogo potenciala regiona [Management of reproduction of financial potential of the region]. Izhevsk, 2005. $20 \mathrm{p}$.

Prokopenko R.A. Ocenka i napravlenija razvitija finansovogo potenciala regiona [Evaluation and directions of development of financial potential of the region]. Volgograd, 2008. $27 \mathrm{p}$.

Stecenko T.O. Analiz regional'noj jekonomiki: uchebnoe posobie [Analysis of regional economy: textbook]. Kyiv, KNEU, 2002. 116 p.

Frolov S.M. Bjudzhetnyj menedzhment i problemy razvitija prigranichnyh territorij: monografija [Budget management and problems of development of border areas: monograph]. Sumy, Publishing House of Sumy state University, 2010.316 p.

Cybul'skaja Je.I. Teoreticheskie osnovy ocenki jekonomicheskogo potenciala predprijatija [Theoretical principles of assessing the economic potential of the enterprise]. BUSINESS-INFORM, 2009, no. 3, pp. 58-61. 


\section{ФИНАНСЫ. БУХГАЛТЕРСКИЙ УЧЕТ}

\section{Information about the Authors}

Dmytriy V. Nekhaychuk, Doctor of Sciences (Economics), Associated Professor, Department of State Finance and Banking, V.I. Vernadsky Crimean Federal University, Prosp. Akademika Vernadskogo, 4, 295007 Simferopol, Russian Federation, dimchikn@mail.ru, https://orcid.org/0000-0002-1915-6393

Alina V. Zhuchik, Postgraduate Student, V.I. Vernadsky Crimean Federal University, Prosp. Akademika Vernadskogo, 4, 295007 Simferopol, Russian Federation, alinazhuchik@yandex.ru, https://orcid.org/0000-0001-5375-0903

\section{Информация об авторах}

Дмитрий Валериевич Нехайчук, доктор экономических наук, доцент кафедры государственных финансов и банковского дела, Крымский федеральный университет им. В.И. Вернадского, просп. Академика Вернадского, 4, 295007 г. Симферополь, Российская Федерация, dimchikn@mail.ru, https://orcid.org/0000-0002-1915-6393

Алина Владиславовна Жучик, аспирант, Крымский федеральный университет им. В.И. Вернадского, просп. Академика Вернадского, 4, 295007 г. Симферополь, Российская Федерация, alinazhuchik@yandex.ru, https://orcid.org/0000-0001-5375-0903 